\title{
Observational study of maternal and fetal outcome in obstetric emergencies admitted to tertiary care centre
}

\author{
Neelima Singh, Sreedevi*, Sushma \\ Department of Obstetrics and Gynaecology, Government General Hospital GGH/GMC Nizamabad, Telangana, India
}

Received: 25 April 2021

Accepted: 28 May 2021

\section{*Correspondence:}

Dr. Sreedevi,

E-mail: drsreedevi111@gmail.com

Copyright: (C) the author(s), publisher and licensee Medip Academy. This is an open-access article distributed under the terms of the Creative Commons Attribution Non-Commercial License, which permits unrestricted non-commercial use, distribution, and reproduction in any medium, provided the original work is properly cited.

\begin{abstract}
Background: Objectives of the current study were to evaluate the risks factors, clinical presentations, the management and maternal and fetal outcome of common obstetric emergencies encountered at Government general hospital Nizamabad, Telangana, from April 2019 to November 2019.

Methods: It is an Observational, hospital-based study done department of obstetrics and gynaecology in 160 cases of obstetric emergencies managed in 8 months study period were reviewed.

Results: Out of 3000 deliveries there were 160 cases of obstetric emergencies giving a percentage of 5.33\%. About $84 \%$ had antenatal care and $16 \%$ had not taken ANC with perinatal mortality of $91.9 \%$ in booked cases. Out of 160 cases of obstetric emergencies, obstetric haemorrhage constituted 94 (58.75\%) cases and among those cases, 23 cases $(24.5 \%)$ were PPH including both atonic and traumatic, abruptio placenta constituted 35 cases $(37.3 \%)$. Out of 160 cases of obstetric emergencies, obstructed labour constituted 29 cases (18.1\%) being a frequent indication for emergency caesarean section, 1 case of septic abortion and 30 cases eclampsia. 29 perinatal deaths giving the perinatal mortality rate as 181 per 1000 live births. One maternal mortality due to rupture uterus. Maternal morbidity was in the form of wound infections which was found in 6 cases $(3.75 \%)$, wound gaping in 2 cases (1.25\%) PPH in 19 cases $(11.81 \%)$, septicaemia in 17 cases $(10.6 \%)$, puerperal pyrexia 6 cases $(3.7 \%)$, vaginal or cervical injury 6 cases (3.7\%), ICU admissions in 9 cases (5.6\%). This morbidity increased the number of days of hospital stay to the patients.

Conclusions: In majority of cases, the complications are preventable and treatable with proper antenatal and intranatal care. Identification of high risks cases, education of people about the importance of supervised pregnancy, delivery and emergency obstetric care will reduce the maternal mortality and morbidity and perinatal mortality and morbidity significantly.
\end{abstract}

Keywords: Obstetric emergencies, Antenatal care, Emergency Obstetric Care, Obstetric haemorrhage, Abruption

\section{INTRODUCTION}

An emergency can be defined as a serious, unexpected and often dangerous situation developing suddenly and demanding immediate attention in order to save life. Obstetrics is unique in that there are two patients to consider and care for, a mother and a baby or fetus. The maternal mortality ratio (MMR), expressed as maternal deaths per 100,000 live births over a given period, is a major measure of quality of obstetric care. Obstetric emergencies are the leading cause of maternal mortality worldwide and particularly in developing countries where literacy, poverty, lack of antenatal care, poor transport facilities inadequate equipment and staffing combine to magnify the problem. ${ }^{1,2}$

The review of maternal and perinatal mortality and morbidity rate is a very sensitive index of the quality of the health care delivery system of a country. This not only widens the knowledge of available Maternal and 
child health services in the community but also helps in analyzing the causes and identifies avoidable factors with an aim to improve maternal health, which in turn will further improve the perinatal care. Every day approximately 810 women died worldwide from preventable causes related to pregnancy and child birth Between 2000 and 2017, the maternal mortality ratio dropped by about $38 \%$ worldwide and $94 \%$ of all maternal deaths occurred were from low and lower middle-income countries. Skilled care before, during and after childbirth can save the lives of women and newborns. ${ }^{3}$

The disparity in demand and supply of quality of health care and factors of timely non-availability of skilled personnel like obstetricians, anesthetists, OT facilities, lack of transport facilities have all lead to increased maternal and perinatal deaths in our country. WHO commends India for its ground breaking progress in recent years in reducing the maternal mortality ratio (MMR) by 77\%, from 556 per 100000 live births in 1990 to 130 per 100000 live births in 2016. India's present MMR is below the millennium development goal (MDG) target and puts the country on track to achieve the sustainable development goal (SDG) target of an MMR below 70 by $2030 .^{4}$

\section{Objectives}

The present study is carried out to know the incidence and nature of obstetrical emergencies and their maternal and perinatal outcome at tertiary care teaching hospital.

\section{METHODS}

Current study was an observational, hospital-based study done department of obstetrics and gynaecology, government general hospital, Nizamabad in 160 Patients with obstetric emergencies.

\section{Sample size}

Sample size was calculated using the formula mentioned below;

$$
\mathrm{n}=\mathrm{z} \alpha^{2} \mathrm{pq} / \mathrm{d}^{2}
$$

Where, $\mathrm{n}$ is the required sample size. $\mathrm{Z} \alpha$ is the standard normal deviate, which is equal to 1.96 at $95 \%$ confidence interval, $\mathrm{p}$ is the prevalence of obstetric emergencies in the study $=28.82 \%, q=100-\mathrm{p}, \mathrm{d}=$ allowable error, $\mathrm{p}=$ $28.82 \%, \mathrm{q}=71.18 \%, \mathrm{~d}=$ allowable error taken as $7 \%$, $\mathrm{n}=$ number of samples is to be studied. Thus, the sample size was calculated to be 160 .

\section{Duration of study}

Study was carried out for 8 months from April 2019 to November 2019.

\section{Inclusion criteria}

Inclusion criteria for current study were; all obstetric emergencies cases admitted directly to the labour room and cases being referred after being handled outside. Antenatal cases as incomplete abortion in shock, APH (placenta previa, abruptio placentae), eclampsia. intranatal cases like hand prolapse, cord prolapse and obstructed labour. Rupture uterus (scar dehiscence, rupture due to obstructed labour/malpresentation/ malposition). Postnatal cases as postpartum hemorrhage, retained placenta, acute inversion of uterus and postpartum eclampsia, booked or unbooked case.

\section{Exclusion criteria}

Surgical complications associated with pregnancy, like acute appendicitis, acute cholecystitis, intestinal perforation, obstruction, renal, ureteric colic, penetrating injury, blunt trauma, medical complications with pregnancy like hepatitis, heart failure, SLE, epilepsy, elective caesarean section were excluded.

\section{Procedure}

On admission to the hospital their detailed history such as name, age, parity, socio-economic status, address, whether booked or unbooked, whether handled at home by untrained dais/relatives at PHC's by health workers, medical officers, or at private nursing home, were noted.

A complete obstetric history was taken, duration of pregnancy, duration of onset of pain, history of vaginal leak, history of bleeding, etc was noted. In referred case, time, date, place of referral, method of interventions like use of IV fluids, use of oxytocin, epidosin, per vaginal examination, ARM, any inducing agent instillations, episiotomy given, use of any instrument, blood transfusion, whether removal of placenta was tried. Reasons for referral, distance travelled, mode of transport, time taken to reach our hospital was noted. A detailed history like past obstetric history, past menstrual history, family history and personal history was noted.

\section{Clinical examinations}

General examinations were made with reference to the stature, nourishment, presence of anemia, cyanosis, edema of feet, signs of shock, signs of toxemia, bladder distensions and bowel distensions. Temperature, pulse rate, blood pressure, hydration, respiratory rate was recorded. A routine examination of respiratory system and cardiovascular system was made. The following obstetric examination was done: The height of the uterus in weeks, presence or absence of contractions, signs of obstructed labour, rupture uterus and ectopic pregnancy, the lie, presentation and position of the fetus, presence of fetal heart sound and if present rate and rhythm was noted. Inspections of the vulva for edema, injury, and for the presence of episiotomy were noted. Per speculum was 
done to note per vaginal leak, and foul-smelling discharge, any bleeding, number of clots, vaginal tears and cervical tears. Per vaginal examination was done to note cervical dilatation, effacement, presence of membranes, presenting part, position and for presence of caput, moulding in vertex presentation and finally pelvic assessment and any disproportion was noted. Modes of delivery vaginal/abdominal were noted. Neonate born alive or dead was noted, if alive, it's Apgar score, weight and for presence of any congenital anomalies was noted. Method of intervention, type of management, according to each emergency case was documented. The mother was followed up in the postnatal period and morbidity in the form of wound sepsis, wound gaping, puerperal sepsis, burst abdomen, fistula formation and also any other morbidity was noted, until she was discharged. The neonate was followed up to early neonatal period for the presence of sepsis, number of days in NICU admission and also early neonatal death was noted. The basic investigations like $\mathrm{HB} \%, \mathrm{BT}, \mathrm{CT}$. Blood grouping and $\mathrm{Rh}$ typing, Urine routine, HIV, HBsAg, LFT, RFT, coagulation profile etc, was done according to the case. The percentages of common obstetric emergency cases among total number of deliveries were calculated. Various parameters like age, parity, literacy, socio economic status, booked/unbooked and other factors contributing to the cases maternal mortality and morbidity, fetal outcome like live birth/ stillbirth/ early neonatal death was studied.

\section{Statistical analysis}

Data entry was done using MS excel and statistically analysed using Statistical package for social sciences (SPSS version 21) for MS windows. Descriptive statistical analysis was carried out to explore the distribution of several categorical and quantitative variables. Categorical variables were summarized with $\mathrm{n}$ $(\%)$, while quantitative variables were summarized by mean \pm SD. All results were presented in tabular form and are also shown graphically using bar diagram or pie diagram as appropriate. The difference in the two groups was tested for statistical significance using parametric tests such as t-test and categorical variables tested by chi square test, $\mathrm{p}$ value less than 0.05 was considered to be statistically significant.

\section{RESULTS}

Out of moribund states, one patient died because of previous 2 LSCS with rupture uterus. In the present study, unbooked cases were $21.3 \%$ patients and booked cases were $78.7 \%$ patients. Out of 160 cases only 50 cases were direct admissions $(31.3 \%)$, the remaining 110 cases $(68.8 \%)$ were referred from surrounding PHCs, Nursing homes, Health workers, outside handled cases by untrained dais. 83 were primigravida, 76 were multiparous and 1 was grandmulti. As youngest age group was 16 years and oldest age was 42 years. Out of 160 cases maximum were between the age group of 21 -
25 years i.e. 85 cases, 36 cases were between 26- 30 years. Teenage pregnancies were 31 and number of pregnancies in age group of $>30$ years was 8 .

Table 1: Total number of booked and unbooked cases.

\begin{tabular}{|lll|}
\hline Parameters & N & $\%$ \\
\hline Types of cases & & \\
\hline Booked & 126 & 78.7 \\
\hline Unbooked & 34 & 21.3 \\
\hline Total & 160 & 100 \\
\hline Admissions & & \\
\hline Direct admissions & 50 & 31.3 \\
\hline Referred cases & 110 & 68.8 \\
\hline Parity wise & & \\
\hline Primi & 83 & 51.9 \\
\hline $2-4$ para & 76 & 47.5 \\
\hline 5 or more & 1 & 0.6 \\
\hline Age group (years) & & \\
\hline $15-20$ & 31 & 19.4 \\
\hline $21-25$ & 85 & 53.1 \\
\hline $26-30$ & 36 & 22.5 \\
\hline $31-35$ & 8 & 5.0 \\
\hline
\end{tabular}

Table 2: Agencies who handled cases in referred patients.

\begin{tabular}{|lll|}
\hline Agencies & $\mathbf{N}$ & $\%$ \\
\hline CHC & 30 & 18.7 \\
\hline AH & 51 & 31.8 \\
\hline Nursing home & 1 & 0.6 \\
\hline PHC & 77 & 48.2 \\
\hline Untrained dais & 1 & 0.6 \\
\hline Total & 160 & 100.0 \\
\hline
\end{tabular}

Table 3: Different types of obstetrics emergencies encountered.

\begin{tabular}{|lll|}
\hline Type & N & $\%$ \\
\hline Placenta previa & 19 & 11.8 \\
\hline Abruptio placentae & 35 & 21.8 \\
\hline Postpartum haemorrhage & 23 & 14.3 \\
\hline Retained placenta & 10 & 6.2 \\
\hline Rupture uterus & 2 & 1.3 \\
\hline Eclampsia & 30 & 18.7 \\
\hline Ectopic pregnancy & 5 & 3.1 \\
\hline Septic abortion & 1 & 0.6 \\
\hline Cord prolapse & 3 & 1.8 \\
\hline Hand prolapse & 3 & 1.8 \\
\hline Obstructed labour & 29 & 18.1 \\
\hline
\end{tabular}

Out of 160 cases, 77 cases were referred from PHC, 51 cases were refereed from $\mathrm{AH}, 30$ cases were referred from $\mathrm{CHC}$, and 1 case was from untrained dais \& 1 from nursing home. Out of 160 obstetric emergencies, the commonest one was obstetric haemorrhage of which 35 cases were abruptio placentae, 23 cases were postpartum 
haemorrhage, 30 cases were eclampsia, 19 cases placenta previa, 10 cases retained placenta, 2 cases rupture uterus, 5 cases ectopic pregnancy, 1 case septic abortion, 3 cases cord prolapse, 3 cases hand prolapse \& 29 cases were obstructed labour. The minimum and maximum distance travelled to reach the hospital ranged between 1 to 45 kms. 79 patients travelled less than $15 \mathrm{kms}$. 46 patients travelled upto $30 \mathrm{kms}$ and 35 patients travelled up to 45 kms. Ranged is from 1 hour to more than 2 hours. 115 patients reached within 2 hours and 45 patients reached more than 2 hours to hospital. In the present study, 125 patients came by ambulance, 35 patients by private transport i.e. by jeep/car/auto.

Table 4: Distance, time and mode of transport of patient to hospital.

\begin{tabular}{|lll|}
\hline Parameters & $\mathbf{N}$ & $\%$ \\
\hline Distance travelled in kms & & \\
\hline $1-15$ & 79 & 49.4 \\
\hline $16-30$ & 46 & 28.7 \\
\hline $31-45$ & 35 & 24.8 \\
\hline Total & 160 & 100 \\
\hline Time taken in hours & & \\
\hline$<2$ & 115 & 71.8 \\
\hline$>2$ & 45 & 28.2 \\
\hline Total & 160 & 100 \\
\hline Mode of transport & & \\
\hline Ambulance & 125 & 78.1 \\
\hline Private & 35 & 21.9 \\
\hline Total & 160 & 100.0 \\
\hline
\end{tabular}

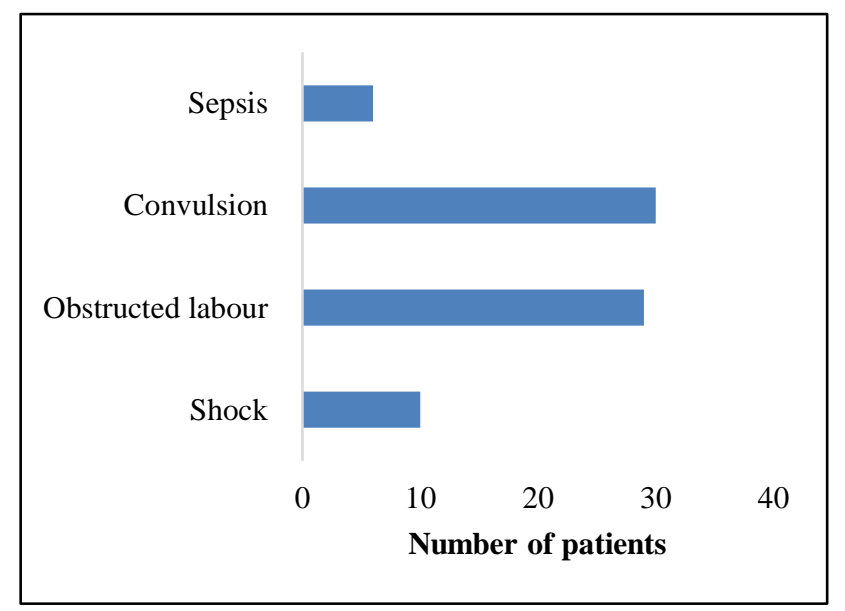

Figure 1: Causes of the moribund state of the patient at the time of admission.

\section{General condition of the mother on admission}

Total $\%$ is not equal to hundred as many patients had more than one conditions present in them). In the present study, 10 patients were in shock, 5 cases had rupture uterus, 30 cases had convulsion and 6 patients had sepsis and 29 cases were in advanced obstructed labour. Out of 160 cases, 51 cases were excluded in which fetus had already delivered and all were in good condition. In the remaining 109 cases FHR was present in 80 cases, FHR was absent in 19 cases and FHR irregular in 10 cases. 17 patients were managed by vaginal delivery, 4 patients by outlet forceps delivery, 1 patient by assisted breech delivery, 10 patients by manual removal of placenta, 31 patients by emergency LSCS, 5 patients by laparotomy, 1 patient by Caesarean hysterectomy, 23 patients by Blood transfusion and conservative management of PPH, 6 patients by Perineal laceration repair and 30 patients by $\mathrm{MgSO}_{4}$ therapy.

Table 5: Condition of the fetus on admission.

\begin{tabular}{|lll|}
\hline Condition & N & $\%$ \\
\hline FHR-present & 80 & 73.4 \\
\hline FHR-absent & 19 & 17.4 \\
\hline FHR-irregular & 10 & 9.2 \\
\hline Total & 109 & 100 \\
\hline
\end{tabular}

In the present study, there were 106 live births, 5 IUDs and 19 stillbirths. Among 106 live births, 5 died in the neonatal period. Thus, there were 29 perinatal death. When analysed with reference to cases birth asphyxia constitute 10 cases of death, prematurity 16 cases and septicaemia in 3 cases. Out of 29 cases of perinatal mortality, 3 cases due to obstructed labour, 13 cases due to eclampsia and 13 cases due to abruptio placentae. 19 cases had perinatal mortality $<37$ weeks and 10 cases had perinatal mortality of $>37$ weeks. Out of 160 cases, obstetric haemorrhage constitutes about 94 cases. 35 cases had abruptio placentae, 23 cases had postpartum haemorrhage, 19 cases placenta previa, 10 cases had retained placenta, 5 cases ectopic pregnancy, and 2 cases had rupture uterus.

Out of 29 cases of obstructed labour, 15 cases had CPD, 7 cases had DTA, 3 cases had OPP, 1case with breech with cord prolapse, 3 cases with transverse lie with hand prolapse. Total percentage will not be hundred, as single patient had more than one complication. Out of 160 cases, outcome was good in 103 patients, 1 mortality due to previous 2 LSCS with rupture uterus and the remaining 56 patients had complications. Out of 160 cases only one died due to previous 2 LSCS with rupture uterus. Out of 160 cases, 16 patients stayed for 1-5 days, 108 cases stayed for 6- 10 days, 32 cases stayed in the hospital for 15 days and 4 patients stayed $>15$ days.

\section{DISCUSSION}

Out of 160 cases, only 126 women had antenatal checkups $(78.7 \%)$ and the rest 34 patients $(21.3 \%)$ had no antenatal check-ups. Rao et al has recorded that even now in $2000 \mathrm{AD}$ almost $50 \%$ of pregnant women get no antenatal care. ${ }^{6}$ The current level of antenatal care in our country is $43.8 \%$ (WHO), which is $78.7 \%$ in the present study. This reflects the good standard of obstetric care in our catchment area. Residence of the case out of 160 
cases, 77 cases were referred from PHC, 51 cases were refereed from $\mathrm{AH}, 30$ cases were referred from $\mathrm{CHC}$, and 1 case was from untrained dais and 1 from nursing home. This shows that lack of availability of skilled birth attendant in rural areas. Rao et al recorded high incidence of home deliveries by untrained midwives in rural areas in his study, due to lack of health services. ${ }^{6}$ Limaye et al has highlighted the negligible availability of high quality of health services at rural areas and hence poor maternal and fetal outcome due to improper management by unskilled birth attendant. $^{2}$

Table 6: Various methods adapted for management of the cases.

\begin{tabular}{|lll|}
\hline Management & N & $\%$ \\
\hline Vaginal delivery & 17 & 10.6 \\
\hline Outlet forceps delivery & 4 & 2.5 \\
\hline Assisted breech delivery & 1 & 0.6 \\
\hline Manual removal of placenta & 10 & 6.3 \\
\hline Em LSCS (1 with rent repaired) & 31 & 19.4 \\
\hline Laparotomy & 5 & 3.1 \\
\hline Caesarean hysterectomy & 1 & 0.6 \\
\hline $\begin{array}{l}\text { Blood transfusion and conservative } \\
\text { management of PPH }\end{array}$ & 23 & 14.3 \\
\hline Perineal laceration repair/cervical & 6 & 3.7 \\
\hline MgSO4 therapy & 30 & 18.7 \\
\hline
\end{tabular}

Table 7: Fetal outcome and perinatal mortality.

\begin{tabular}{|lll|}
\hline Parameters & N & $\%$ \\
\hline Fetal outcome & & \\
\hline Fresh stillborn & 19 & 11.9 \\
\hline Intrauterine death & 5 & 3.1 \\
\hline Live birth & 106 & 66.2 \\
\hline NICU & 30 & 18.8 \\
\hline Total & 160 & 100.0 \\
\hline Causes for perinatal mortality & & \\
\hline Birth asphyxia & 10 & 34.5 \\
\hline Prematurity & 16 & 55.2 \\
\hline Septicaemia & 3 & 10.3 \\
\hline Total & 29 & 100 \\
\hline Obstetric events with perinatal mortality & \\
\hline Obstructed labour & 3 & 10.4 \\
\hline Eclampsia & 13 & 44.8 \\
\hline Abruptio & 13 & 44.8 \\
\hline $\begin{array}{l}\text { Perinatal mortality in relation to gestational age } \\
\text { (weeks) }\end{array}$ & \\
\hline$>37$ & 10 & 34.5 \\
\hline$<37$ & 19 & 65.5 \\
\hline
\end{tabular}

Primigravida constituted 83 cases (51.9\%) and multiparous women (P2- P4) were 76 cases $(47.5 \%)$ and grand multi was 1 case $(0.6 \%)$. In our study, most of the postpartum haemorrhage occurred in the category of multiparous women because of high fertility in that group. Limaye et al in his study had primigravida constituting $44.8 \%$, grand multi $(13.2 \%)$ and multiparous
$(42.00 \%) .^{2}$ The higher parity in this study 63 got admitted for retained placenta. Prasad et al there were primipara $(37.5 \%)$, multipara $(55.35 \%)$ and $(7.14 \%)$ were grand multipara. ${ }^{5}$ Gupta et al found $(52.17 \%)$ primi-gravida and Goswami et al, also found that majority (47\%) were primi -gravida. ${ }^{7,8}$ Bindal et al also found the maximum number of patients $(50 \%)$ were multi-gravida. ${ }^{9}$

Table 8: Analysis of obstetric haemorrhage cases.

\begin{tabular}{|lll|}
\hline Parameters & N & $\%$ \\
\hline Causes & & \\
\hline Placenta previa & 19 & 20.2 \\
\hline Abruption placentae & 35 & 37.3 \\
\hline Postpartum haemorrhage & 23 & 24.5 \\
\hline Rupture uterus & 2 & 2.1 \\
\hline Rupture ectopic pregnancy & 5 & 5.3 \\
\hline Retained placenta & 10 & 10.6 \\
\hline Total & 94 & 100 \\
\hline Obstructed labour & & \\
\hline Cephalopelvic disproportion & 15 & 51.7 \\
\hline Deep transverse arrest & 7 & 24.1 \\
\hline Occipito posterior position & 3 & 10.3 \\
\hline Breech with cord prolapse & 1 & 3.4 \\
\hline Transverse lie with hand prolapse & 3 & 10.3 \\
\hline Total & 29 & 100 \\
\hline
\end{tabular}

Table 9: Maternal morbidity.

\begin{tabular}{|lll|}
\hline Parameters & N & $\%$ \\
\hline Morbidity & & \\
\hline Wound infections & 6 & 3.75 \\
\hline Wound gaping & 2 & 1.25 \\
\hline Septicaemia & 17 & 10.6 \\
\hline PPH & 19 & 11.8 \\
\hline Peuperal pyrexia & 6 & 3.7 \\
\hline Vaginal/cervical/vulval injury & 6 & 3.7 \\
\hline Maternal mortality & & \\
\hline Previous 2 LSCS with rupture uterus & 1 & 0.6 \\
\hline
\end{tabular}

Out of 160 cases, age group between 21 to 25 years constitute maximum number of cases $(53.1 \%)$. They were considered as low risk. Each pregnancy whether teen or otherwise has to be considered important, as maternal complications cannot be predicted and emergency obstetric care (EMOC) should be made available to all pregnant women at all times, since child birth can take place at any time, and also complications can occur at any time as observed by Kumar et al. ${ }^{10,11}$ Limaye et al had age group between $15-30$ years as $89.2 \%$ and more than 35 as $3.2 \% .^{2}$ In a study by Pokharel et al age of patients ranged from $15-55$ years with approximately $43 \%$ in the 25-34 years category. ${ }^{12}$ Most of the patients admitted to our institution were belonged to low socioeconomic status and were illiterate and hence were ignorant of the available health services. This shows that social factors play a significant role for access to better 
obstetric care as many of them had taken intranatal care from a relative or untrained dais. Limaye et al similarly showed that factors like literacy, low socio-economic status played a role in utilizing the available health services. $^{2}$ Most of the cases referred from PHC, indicating poor availability of health personnel at rural areas. In our study, $70 \%$ of the cases referred from PHC and $0.9 \%$ are direct referred by untrained dais which approximately correlates with the study of Mughal et al which is about $70 \% .{ }^{13}$ Cases who are handled by private nursing homes, PHC and usually they were referred late when emergency occurred, due to lack of blood transfusion, anaesthetic facilities and for the nonaffordability of LSCS. This depicts the fact that high cost is a barrier for better health care in rural areas also shown by Kumar et al. ${ }^{10}$

All cases were referred from surroundings like PHCs, Nursing homes, untrained dais and health worker, with different obstetrics emergencies like obstetric haemorrhage, eclampsia, $\mathrm{PPH}$, retained placenta, septic abortion, obstructed labour etc. In our study, majority of the patients referred due to obstetric haemorrhage because of the inadequate blood transfusion facilities in rural areas. Limaye et al has reported that majority of patients referred after prolonged labour leading to obstructed labour which is contradictory to the present study. ${ }^{2}$

Minimum distance travelled was less than $3 \mathrm{kms}$ and maximum was $45 \mathrm{kms}$. Out of 160 cases, 79 patients had to travel within $15 \mathrm{kms}$ and 46 patients had to travel within 16-30 kms and 35 patients had to travel within 31$45 \mathrm{kms}$. In our study, majority of the patients travelled less than $15 \mathrm{kms}$ so proper obstetric care can be given to them and prevent from hazardous complications. Bhatt et al in their study, also quotes that lack of timely transport and communications results in higher maternal mortality in rural areas. ${ }^{14}$ Ranged from less than 1 hour to more than 4 hours, 115 cases reached within 2 hour and 45 cases reached within 2-4 hours to reach the hospital. In present study, majority of the patients reached within 2 hours, so according to Patel in his study found out that avoidance of delay in reaching hospital and improvement of transportation and communication services can reduce the MMR significantly. ${ }^{15}$ In the present study, Out of 160 cases, 77 cases were referred from PHC, 51 cases were refereed from $\mathrm{AH}, 30$ cases were referred from $\mathrm{CHC}$, and 1 case was from untrained dais and 1 from nursing home and 1 patient died due to previous 2 LSCS with rupture uterus. Anemia which is a preventable factor with regular ANC was highly prevalent in the present study, which increased the incidence of mortality and morbidity. Rathicharu et al in their study also found out $45 \%$ of the patients was admitted in critical condition which is correlating with the present study. ${ }^{16}$

In the present study, FHR was present in 80 cases (73.4\%). FHR was absent in 19 cases $(17.4 \%)$ and FHR with tachycardia, bradycardia and irregularity indicating
66 fetal distress in 10 case $(9.2 \%)$. In Limaye et al series, FHR was present in $65.4 \%$, absent in $13.60 \%$ and irregular in $20 \% .^{2}$ Thus, in present study, majority of foetuses were in jeopardized on arrival mainly due to APH, eclampsia, and obstructed labour. So, there is increase perinatal mortality in present study. Perinatal mortality includes both late fetal deaths (still births) and early neonatal deaths. In current study, there were 106 live birth, 5 IUD and 19 still birth, out of 106 live birth, 5 died in the neonatal period, thus there were 29 perinatal death giving the perinatal mortality rate in our study as 285.71 per 1000 live births. Limaye et al in his series also had PNMR as 282.3 per 1000 live births in unbooked cases as against 70 per 1000 live birth in booked cases which is correlating with the present study. ${ }^{2}$ When analysed with reference to the obstetric events causing perinatal death, prematurity due to eclampsia and abruptio placenta contributed as the major cause. In a study by Prasad et al perinatal outcome was just satisfactory $(60.8 \%)$ had live births and $(5.88 \%)$ were still born. ${ }^{5}$ Najam et al found $(65.2 \%)$ had live birth and $34.76 \%$ were still born. ${ }^{17}$ In a study by Pal et al the overall incidence of low-birth-weight baby was $26.96 \%$ and perinatal mortality was $30.33 \% .^{18}$ The incidence of perinatal mortality and low birth weight babies are lower in the last 4 years when compared to earlier studies.

Out of 160 cases only one patient died due to previous 2 LSCS with rupture uterus. This reduction in maternal mortality could be because of early referral, less time taken to reach the hospital and timely management of the case. Gadhiali et al in their study reported $1.2 \%$ maternal mortality which is correlating with the present study. ${ }^{19}$ Sharma et al in her study also reported $1.55 \%$ maternal mortality. ${ }^{20}$ Prasad et al in their study reported $2.3 \%$ maternal mortality. ${ }^{5}$ In a study by Pal et al the overall case fatality rate was $6.05 \%$ and eclampsia contributed $27.85 \%$ of all maternal deaths during the last two years of the study period. ${ }^{18}$ Bindal et al also found in their study that maternal death occurred in $(2.2 \%)$. $^{9}$ Park mentioned that, there is an inverse relationship between lifetime risk of maternal death and the availability of the trained birth workers during pregnancy and at time of delivery. He also mentioned that it is a tragic situation, as these deaths are not caused by disease but occurred during or after natural process and it can be prevented if careful harmful birth practices are avoided. ${ }^{21}$

Out of 160 cases of obstetric emergencies obstetric haemorrhage constituted 94 cases, among 94 cases, 23 cases $(24.5 \%)$ were PPH including both atonic and traumatic out of which is due to placenta percreta. Abruptio placenta constituted 35 cases (37.3\%), placenta previa 19 cases $(20.2 \%)$, rupture uterus 2 cases $(2.1 \%)$, ruptured ectopic 5 cases $(5.3 \%)$ and retained placenta in 10 cases $(10.6 \%)$. Thus, the present study shows that obstetric haemorrhage is still a common cause in rural area which leads to maternal mortality. In the present study maternal mortality is also due to obstetric haemorrhage. Out of 160 cases of obstetric emergencies, 
obstructed labour constituted 3 cases (10.4\%) being a frequent indication for emergency caesarean section. CPD was the commonest cause followed by DTA, OPP, breech, compound presentation which showed with Kamalajayaram series. ${ }^{22} 15$ cases of obstructed labour underwent emergency caesarean section including one case with caesarean hysterectomy, forceps delivery in 4 cases, and 1 case had assisted breech delivery and no case for destructive operations. This shows that instrumental and destructive operatives were decreased in present study. Gupta observed that obstructed labour causing rupture uterus is the commonest indication for caesarean hysterectomy which can be correlated with the present study. ${ }^{7}$ Maternal morbidity was in the form of wound infections was found in 6 cases $(3.75 \%)$, wound gaping in 2 cases $(1.25 \%), \mathrm{PPH}$ in 19 cases $(11.8 \%)$, septicaemia in 17 cases $(10.6 \%)$, puerperal pyrexia 6 cases $(3.7 \%)$, vaginal or cervical injury 6 cases $(37 \%)$. This morbidity increased the number of days of hospital stay to the patients. Number of hospitals stay, out of 160 cases, 16 patients $(10 \%)$ stayed for $1-5$ days, 108 patients $(67.5 \%)$ stayed for 6-10 days. 32 patients (20\%) stayed in the hospital up to 15 days due to wound infections, severe anemia and puerperal sepsis. 4 cases $(2.5 \%)$ stayed for more than 15 days due to wound gaping. Thus, increased number of hospital stay was an additional economic burden for already economically under privileged people.

\section{CONCLUSION}

The majority of the pregnancies in the sample were unplanned. Pregnancies among teenagers were documented in the study. Rural areas accounted for more than half of all obstetric emergencies. The majority of admissions experienced a delay of more than 5 hours in reaching this hospital. Access to antenatal health care facilities was hampered by a number of factors, one of which was ignorance. Pregnant women's health education, including the value of early ANC booking and routine check-ups, the diagnosis of high-risk pregnancy and prompt referral, and the provision of fully functioning first referral units and transportation facilities for these emergency patients. Availability of skilled medical professionals round the clock in these First referral units are the need of the hour.

\section{Funding: No funding sources}

Conflict of interest: None declared

Ethical approval: The study was approved by the Institutional Ethics Committee

\section{REFERENCES}

1. Campell S, Lee C. Obstetric emergencies. In: Campell SL, eds. Obstetrics by ten teachers. 17th ed. London: Arnold Publisher; 2000:303- 7.

2. Limaye HR. Maternal and fetal outcome in obstetric emergency cases referred from rural areas. J Obstet Gynaecol. 1982;32:520-9.
3. Trends in maternal mortality: 2000 to 2017. Available at: https://www.who.int/reproductive health/publications/maternal-mortality-20002017/en/. Accessed on 20 February 2021.

4. Mohapatra A, Gomare M. A critical appraisal of the maternal and child health scenario in a metropolitan city in India with reference to achievements of millennium development goals. J Family Med Prim Care. 2019;8:995-1001.

5. Prasad D, Nishat H, Tiwary B, Swet N, Sinha A, Goel N. Review of obstetrical emergencies and fetal out come in a tertiary care centre. Int J Res Med Sci. 2018;6:1554-8.

6. Rao BK. Vesicovaginal fistula: A study of 269 cases. J Obstet Gyn. 1972; 22:536-41.

7. Gupta PR, Chaudhary SN, Gonnadee NV. Maternal and fetal out come in referred patients to tertiary care centre centre. Sch J App Med Sci. 2016;4(5c):162463.

8. Goswami P, Bindal J, Chug N. To study pattern of obstetric cases referred at tertiary care centre in Central india. Int $\mathbf{J}$ Reprod Contracept Obstet Gynecol. 2017;6(6):2370-4.

9. Bindal J, Agrawal N, Sharma DC. Overview of referred obstetric patients and their outcome in tertiary care Hospital. JMSCR. 2017;5(5):452-9.

10. Kumar R. Prevention of maternal mortality why success eludes us. Indian J Public Health. 2002;46:37.

11. Najam R, Gupta S, Chowdhury H. Pattern of obstetrical emergencies and fetal outcomes in a tertiary care center. Acta Med Int. 2015;2(1):105.

12. Pokharel HP, Dahal P, Rai R, Budhathoki S. Surgical emergencies in obstetrics and gynaecology in a tertiary care hospital. J Nepal Med Assoc. 2013; 52(189):213-6.

13. Mudgal S, Rathee S, Malik S. Birth practices in rural Haryana and urban Haryana. J Obstet Gynaec. 1990;40:742-5.

14. Bhatt R. Maternal Mortality. J Obstet Gynecol. 1997; 47:211.

15. Patel D. Description of inter-institutional referrals after admission for labor and delivery: a prospective population based cohort study in rural Maharashtra, India. BMC Health Services Res. 2017;17:360.

16. Charu R, Kamal G, Neelu S. Review of referred obstetric cases maternal and perinatal outcome. Bombay Hospital J. 2010;52(1):45-9.

17. Najam R, Gupta S, Chowdhury H. Pattern of obstetrical emergencies and fetal outcomes in a tertiary care center. Acta Med Int. 2015;2(1):105.

18. Pal A, Bhattacharyya R, Adhikari S, Roy A, Chakrabarty D, Ghosh P. Eclampsia scenario in a hospital: a 10 years study. Bangla Med Res Council Bull. 2011;37(2):66-70.

19. Gadhiali MV, Lenya NR, Shankhalkar PC. Maternal care and mortality. J Obstet Gynaec. 2015;45:235-9.

20. Sharma S. Multiparametric study of obstetric and gynaecological emergency cases referred to a tertiary 
care centre. Indian J Med Res Pharm Sci. 2015;2:1420.

21. Park K. Park's Textbook of preventive and social medicine. 25th ed. Jabalpur: Banarsidas Bhanot Publishers; 2019.
22. Kamalajayaram V. Obstructed labour: Analysis of 126 cases. J Obstet Gynaec. 1999;43:60-3.

Cite this article as: Singh N, Sreedevi, Sushma. Observational study of maternal and fetal outcome in obstetric emergencies admitted to tertiary care centre. Int J Reprod Contracept ObstetGynecol

2021;10:2712-9. 